\title{
A avaliação do nível de habilidades para trabalhar em equipe entre professores universitários
}

\author{
Fernanda Pasquoto e Soura - Universidade Federal do Rio Grande do Sul \\ Janine Kieling Monteiro - Universidade V ale do Rio dos Sinos \\ Gisele Beatriz Zatt Elgues - Universidade Luterana do Brasil
}

\begin{abstract}
Resumo
Este estudo procurou avaliar a habilidade para o trabalho em equipe em 78 professores universitários das ciências da saúde e exatas. Utilizou-se o Questionário de Habilidades para Trabalhar em Equipe para avaliar as categorias: preocupação com a equipe, características de liderança, formas de comunicação, preocupação com a tarefa e preocupação com o humano. Realizaram-se análises estatísticas de freqüência e teste t de Student. Nos resultados destaca-se que as habilidades para o trabalho em equipe são positivamente valorizadas no exercício da docência. Nas categorias específicas, preocupação com a tarefa obteve o escore padronizado mais alto, enquanto preocupação com a equipe, o mais baixo. A área das ciências da saúde alcançou resultados mais altos em preocupação com o humano do que a das exatas. Discutem-se aspectos que ratificam a importância da avaliação psicológica nessa área de atuação, contribuindo tanto nas tarefas de diagnóstico como no desenvolvimento dessas habilidades.

Palavras-chave: Habilidades; Trabalho em equipe; Professores universitários.
\end{abstract}

\section{The evaluation of the level of abilities to work in team between university professors}

\begin{abstract}
The purpose of this study was to assess 78 university teachers from the areas of Health Sciences and Natural Sciences in their abilities for teamwork. The Teamwork Abilities Assessment Form was used to assess such categories as: concern with the team, leadership characteristics, ways of communication, concern with the task, and concern with the human aspects. Statistical analysis of frequency and Student's t test were performed. Results have shown that abilities for teamwork are positively assessed in the teaching profession. In the specific categories, concern with the task obtained the highest standardized score, while concern with the team scored lowest. The area of health sciences scored higher than natural sciences regarding concern with the human aspects. Aspects that validate the importance of psychological assessment in this professional area are discussed and contribute not only to the tasks of diagnosis but to the development of these abilities as well.
\end{abstract}

Keywords: Abilities; Teamwork; University teachers.

\section{Trabalho em equipe}

Em diferentes categorias profissionais, independentemente da área, percebe-se, cada vez mais, a importância do trabalho em equipe, dado que esforços individuais não garantem, por si só, o êxito nem o alcance, com eficácia, de qualquer objetivo. Para muitos, o trabalho em equipe configura-se como um desafio ou como uma habilidade a ser desenvolvida.

A docência no âmbito universitário hoje exige, cada vez mais, uma atuação em nível interdisciplinar e também uma convivência mais próxima na relação professor-aluno, o que acaba trazendo como conseqüência a valorização do trabalho em equipe, tanto na relação professor-professor como na relação professoraluno.
$\mathrm{Na}$ atualidade, o trabalho em equipe tem sido extremamente valorizado. Como bem aponta Parker (1994), as equipes estão em toda a parte e ocupam um papel primordial na vida profissional e pessoal da sociedade como um todo.

Inúmeras pesquisas, desenvolvidas para identificar as principais características do profissional do futuro, apontam a habilidade para trabalhar em equipe como uma das favoritas, pois modelos de organização mais integrados, nos quais a informação e os resultados são compartilhados, estão se consolidando cada vez mais (Fleury, 2002).

Conforme descreve Spector (2003), qualquer trabalho que exija ações coordenadas e envolva mais de uma pessoa configura-se como trabalho em equipe. Em vários locais, encontram-se grupos de pessoas que,

1 Endereço para correspondência:

Avenida Neuza Goulart Brizola, 500/304 - Bela Vista - 90460-230 - Porto Alegre-RS

E-mail: fegps@terra.com.br 
apesar de trabalharem relativamente de forma independente, ao entrarem em contato uns com os outros, acabam por afetar o comportamento daqueles com quem interagem, como, por exemplo, professores universitários e vendedores, entre outros.

Para tanto, Moscovici (2003a, 2003b) enfatiza a importância de uma comunicação efetiva, onde opiniões divergentes são estimuladas e, por conseguinte, as diferenças individuais, quanto a habilidades, são compartilhadas, na direção e alcance dos resultados. Inúmeros sentimentos permeiam essa relação e, quando positivos, tendem a provocar o aumento da interação e cooperação, repercutindo em favor das atividades e propiciando maior produtividade.

Vários autores (Marras, 2000; Spector, 2003) ressaltam que existe uma diferença crucial entre o trabalho em grupo e o trabalho em equipe. Assim, todas as equipes são grupos, mas nem todos os grupos são equipes. $\mathrm{Na}$ equipe, as pessoas trabalham juntas, se envolvem na tarefa de todos, numa lógica de total comprometimento; no grupo, por sua vez, cada um executa e se responsabiliza pelas tarefas designadas pelo líder.

Nesse sentido, Moscovici (2003a) refere que o alicerce fundamental para o desenvolvimento de uma equipe é o desenvolvimento interpessoal. Segundo a autora, "as habilidades interpessoais são facilitadoras de processos grupais básicos, tais como: comunicação, liderança, processo decisório, negociação, administração de conflitos e análise de processo" (p. 103).

Goulart (2002), paralelamente, assinala que o sucesso das equipes apóia-se em alguns aspectos fundamentais:

comunicação, cooperação, compartilhamento de conbecimentos, capacidade de estabelecer relacionamentos interpessoais, abertura para compreender o ponto de vista do outro e habilidade de ouvir e expressar-se de modo claro e consistente. (p. 261)

\section{Professores universitários}

Para Bock (1996), ser professor, para além de transmitir conhecimentos, é, acima de tudo, ser um educador, compromissado com a formação do aluno, em relação a valores morais e éticos, além de servir como um modelo de liderança a ser seguido.

O mesmo autor afirma, ainda, que todo o profissional que lida com pessoas é agente de saúde mental. Nessa ótica, o professor também o é, por estar diretamente envolvido na tarefa de formar pessoas.

Para Isaia e Bolzan, (2004, p. 8),

A docência superior ocorre no espaço de articulação entre modos de ensinar e aprender, em que professores e alunos intercambiam as funçôes de ensinantes e aprendentes, não tendo, nenhum deles, o monopólio exclusivo de uma delas. Nesse sentido, pode-se falar em aprendizagem compartilhada, seja relativa ao processo construtivo de ser professor do ensino superior, seja em relação ao processo inicial de preparação dos alunos como futuros profissionais em suas diversas áreas de atuação.

De acordo com Vasconcelos (1996), não há como ignorar que a essência de qualquer ação didáticopedagógica está necessariamente sustentada na relação professor-aluno. Corroborando esse pressuposto, Delors (2003) ressalta que o professor deve passar do papel de "solista" ao de "acompanhante", tornando-se não mais alguém que transmite conhecimentos, mas que ajuda a encontrar, organizar e gerir o saber.

Para tanto, tal qual Perrenoud (2000) aponta:

O trabalho em conjunto torna-se uma necessidade, ligada mais à evolução do oficio do que a uma escolha pessoal. Há cada vez mais professores, jovens ou adolescentes, que desejam trabalhar em equipe, visando niveis de cooperação mais ou menos ambiciosos. Alguns deles excluem radicalmente 0 trabalho solitário, outros são mais ambivalentes, mas vêem as vantagens de uma cooperação regular se esta lhes deixar uma autonomia suficiente. (Perrenoud, 2000, p. 80)

Para Delors (2003), o trabalho em equipe é indispensável, pois poderá melhorar a qualidade da educação, permitindo uma maior e melhor adequabilidade ao singular e às características peculiares dos diferentes grupos de alunos.

Já na relação com os colegas, é de suma importância que o professor trabalhe, sempre que possível, de forma integrada com as demais disciplinas, com o objetivo de propiciar vivências suficientemente significativas a ponto de modificar as representações do ensino e da aprendizagem (Enricone, 2004).

Conforme Sadalla e colaboradores (2005), o processo de ensino-aprendizagem deve ser construído cotidianamente, não só a partir das teorias que fundamentam sua ação, mas também a partir de reflexões que devem permear a formação docente, pois a ação de compartilhar com os pares é a base estruturadora de um desenvolvimento profissional.

Gil (1997) salienta algumas características pessoais que são reconhecidas, pela maioria dos especialistas em educação, como desejáveis para os professores universitários: físicas e fisiológicas; comportamentais (estabilidade emocional, iniciativa, cooperação, versatilidade, paciência); e intelectuais.

Por fim, Perrenoud (2000) destaca, no seu texto sobre as novas competências exigidas no ensino, que para 
a realização de determinados projetos necessita-se buscar o "verdadeiro trabalho em equipe", que começa quando os membros se afastam do "muro de lamentações" para agir, utilizando toda a zona de autonomia disponível e toda a capacidade de negociação, afastando as restrições institucionais e buscando obter os recursos e os apoios necessários.

Logo, considerando a importância do trabalho em equipe, especialmente para a docência, este estudo tem como objetivo investigar, entre professores universitários das áreas das ciências da saúde e exatas, as habilidades necessárias para o trabalho em equipe. $\mathrm{E}$ também verificar outras possíveis associações entre estas habilidades e as variáveis: área de atuação, sexo, faixa etária e tempo de docência.

\section{Método}

Trata-se de uma pesquisa com delineamento não experimental, de natureza exploratório-descritiva. De acordo com Gil (1995) e Lima (1999), este tipo de estudo não interfere diretamente nos fenômenos que são investigados, tendo por objetivo a sua exploração e descrição, correlacionando variáveis, proporcionando, assim, uma visão mais ampla do problema.

\section{População e amostra}

A população em estudo foram professores universitários. Dessa população, recortou-se uma amostra de 78 professores, sendo 40 da área das ciências da saúde e 38 da de exatas, lotados em diferentes cursos de graduação. Compunham o grupo da área das ciências da saúde os seguintes cursos: psicologia, fonoaudiologia, farmácia, enfermagem, odontologia, fisioterapia e medicina. E na área das ciências exatas fizeram parte do estudo os cursos de: matemática; química; análise de sistemas, arquitetura; economia; engenharias elétrica, agrícola, civil e mecânica.

$O$ processo de amostragem foi do tipo nãoprobabilístico, por acessibilidade (Gil, 1995), uma vez que nenhum mecanismo aleatório foi utilizado para sorteio das unidades amostrais.

Dentre as características gerais dos participantes pode-se destacar que: $65,4 \%$ corresponde ao sexo feminino e 34,6\% ao masculino; a idade variou de 25 a 62 anos, sendo 41 anos a idade média; o tempo de docência foi de 1 ano a 32 anos, com média de 10,2 anos e a formação acadêmica foi de superior completo a doutorado, com a maioria sendo de mestrado (41\%).

$\mathrm{Na}$ área das ciências da saúde, a maioria (80\%) da amostra está representada por professores do sexo feminino. $\mathrm{Na}$ área das exatas, entretanto, encontra-se $50 \%$ de professores do sexo feminino e $50 \%$ do masculino.

Psico-USF, v. 12, n. 2, p. 157-164, jul./ dez. 2007
Instrumento

O instrumento utilizado para a coleta de dados foi o Questionário de Habilidades para Trabalhar em Equipe HTE, desenvolvido em estudo anterior por Monteiro, Ribeiro, Serafim e Souza (2002). Trata-se de uma escala do tipo Lickert, com 42 itens, onde o sujeito deve escolher a alternativa de 1 a 5 que melhor descreva o seu modo de agir e pensar. Ela varia, portanto, do valor 1 - discordo muito até o valor 5 - concordo muito.

$\mathrm{O}$ instrumento avalia diferentes características e habilidades necessárias para o trabalho em equipe, agrupadas em cinco dimensões: preocupação com a equipe, características de liderança, formas de comunicação, preocupação com a tarefa e preocupação com o humano. Em todas as categorias existem questões diretas e questões indiretas; para diminuir o efeito de sugestão e a possibilidade de manipulação das respostas, nas questões indiretas utiliza-se a inversão do valor desses itens. Pode ser aplicado de forma individual e/ou coletiva, com tempo livre estimado, em média, entre 15 a 20 minutos.

Quanto à descrição das dimensões avaliadas: a preocupação com a equipe diz respeito a estar motivado e comprometido com o trabalho em grupo, ser flexível nos seus conceitos e com os outros componentes do grupo, ser acessível para trocar experiências. Outra dimensão estudada é características de liderança, tais como: assumir responsabilidade e orientação para direcionar a equipe quando necessário, inspirar confiança e segurança, delegar tarefas e responsabilidades, deixando os outros se desenvolverem no trabalho e ter habilidade para administrar conflitos. Outro fator avaliado, formas de comunicação, envolve tanto a comunicação verbal, como expor, ouvir e pedir opiniões, quanto a postura de ter senso de humor e demonstrar simpatia. A preocupação com a tarefa está relacionada à pessoa ter iniciativa e comprometimento para lidar com as tarefas e ações necessárias, interessar-se por tudo o que faz, ser eficiente e estar atualizada em conhecimentos. A preocupação com o humano diz respeito a características como: ser solidário, ajudar os outros, ser ético, ser afetivo, gentil e compreensivo.

Ressalta-se, por fim, que o referido instrumento está em fase de validação, onde se verificará seus índices de validade e precisão com vistas a atender aos parâmetros psicométricos que garantem a sua cientificidade (Pasquali, 1999, 2003). Para a interpretação dos resultados, serão utilizadas normas intragrupo, de acordo com sexo, faixa etária e áreas estudadas (empresa, escola e instituições esportivas).

\section{Procedimento para coleta de dados}

Primeiramente, o trabalho foi encaminhado e aprovado pelo Comitê de Ética da ULBRA (sob o 
número do protocolo 2004-431H). Posteriormente, foi entregue à direção dos cursos uma carta de apresentação da pesquisa, com o intuito de obter o consentimento para a coleta de dados, que indicou os professores que poderiam fazer parte do estudo.

Resguardando os princípios éticos, foi entregue, a cada professor, um Termo de Consentimento Livre e Esclarecido, que foi assinado, de modo a declarar o interesse em participar do estudo, de forma voluntária e espontânea. Assim, garantiu-se o esclarecimento dos objetivos e procedimentos utilizados na pesquisa, que a identidade dos mesmos seria preservada e que os dados obtidos seriam utilizados exclusivamente para fins de pesquisa.

\section{Procedimento para análise dos dados}

Os dados de identificação, os escores brutos obtidos em cada uma das categorias que o instrumento avalia, bem como o escore total foram lançados numa planilha para estruturação, através do programa Excel, do banco de dados. Para as análises estatísticas (descritivas e inferenciais) foi utilizado o software Statistical Pakage for Social Sciences (SPSS for Windows, versão 10.0).

Foram utilizadas as seguintes técnicas estatísticas: tabelas de freqüência simples e cruzadas, medidas de tendência central e de variabilidade, gráfico de setores, barras e histograma, e teste t de Student.

\section{Resultados}

Antes de iniciar a apresentação, é fundamental enfatizar que o instrumento utilizado para a coleta dos dados está em fase de validação, portanto, os resultados desta amostra não podem ser comparados a critérios específicos de referência, ou seja, aos dados normativos que, a priori, constam sempre nos manuais. Foram analisados, então, apenas entre si.

No que diz respeito aos resultados, inicialmente serão tratados os dados mais abrangentes e, posteriormente, os específicos. $\mathrm{Na}$ dimensão total do instrumento, composta por 42 itens com alternativas de resposta do valor 1 (discordo muito) até o valor 5 (concordo muito), os escores brutos totais podem variar entre 42 e 210 pontos. Apesar de não ser possível fazer comparações a critérios normativos de referência, a Figura 1 mostra que, em relação ao total de pontos brutos, os escores da maioria dos professores situam-se entre 160 e 190 pontos, variando a escala de 42 a 210 pontos. Portanto, os professores obtiveram um resultado geral com pontuação bem elevada, indicando que eles se avaliaram com vários atributos indicados para o trabalho em equipe.

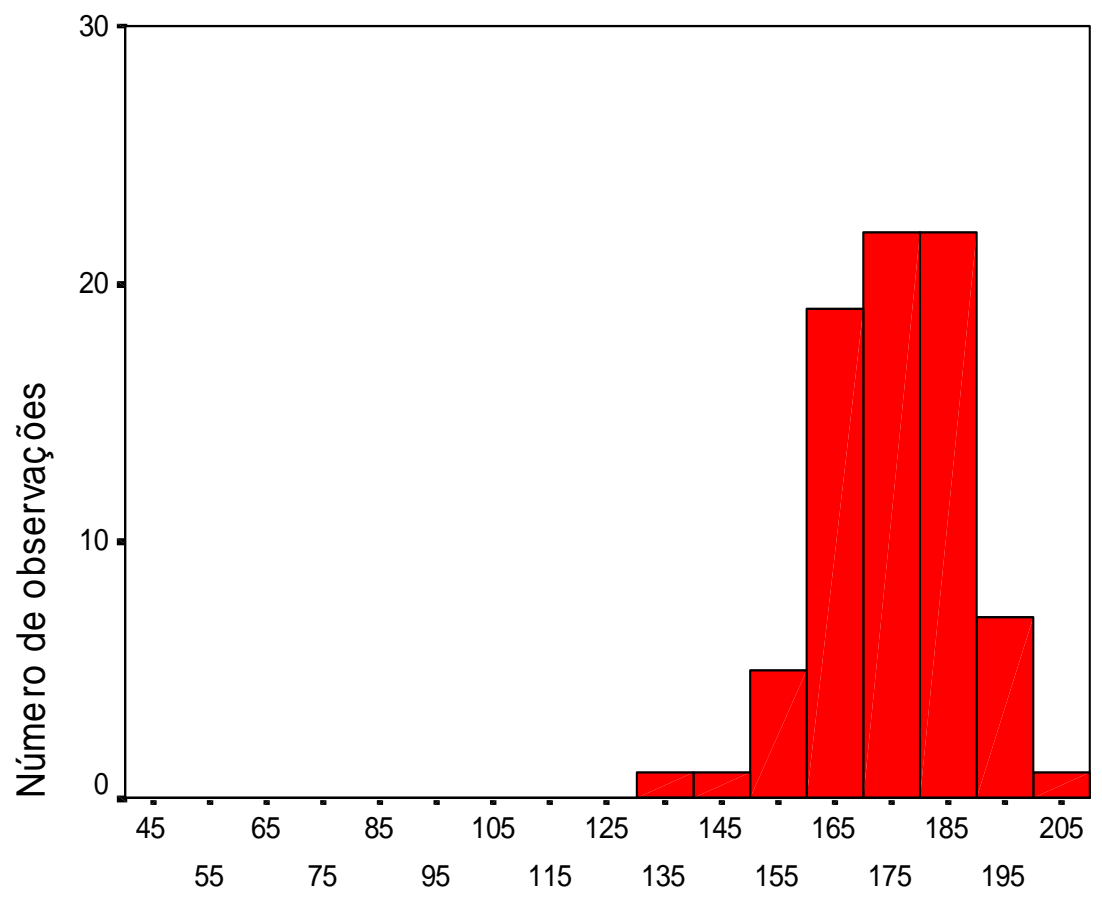

HTE Total

Figura 1 - Histograma para HTE total 
Já na Tabela 1 são apresentadas as médias brutas e os escores médios padronizados (a partir do número de itens) em cada uma das cinco categorias específicas avaliadas pelo HTE e o escore total.

Tabela 1 - Escores padronizados por categoria

\begin{tabular}{lccc}
\hline \multicolumn{1}{c}{ Categoria HTE } & N & Média & Escore médio padronizado \\
\hline Preocupação com a equipe & 78 & 30,83 & 3,85 \\
Características de liderança & 78 & 29,10 & 4,16 \\
Formas de comunicação & 78 & 40,04 & 4,00 \\
Preocupação com a tarefa & 78 & 39,77 & 4,42 \\
Preocupação com o humano & 78 & 34,86 & 4,36 \\
\hline Total & 78 & 174,60 & 4,16 \\
\hline
\end{tabular}

Os resultados evidenciam que a categoria preocupação com a tarefa foi a mais valorizada $(4,42)$, seguida, em ordem decrescente, por preocupação com o humano (4,36), características de liderança $(4,16)$, formas de comunicação $(4,00)$ e preocupação com a equipe $(3,85)$.

Com base nas comparações de interesse realizadas através do teste $t$ de Student, verificou-se que, nas cinco categorias específicas, não há diferença significativa entre os professores da área das ciências da saúde e das exatas. No entanto, é importante observar que, entre os das ciências da saúde, a preocupação com o humano $(\mathrm{p}=0,068)$ está bem próxima do significativo $(\mathrm{p}=0,05)$.

Tabela 2 - Teste t de Student para comparação dos escores por gênero

\begin{tabular}{lllllll}
\hline \multicolumn{1}{c}{ Categoria HTE } & Sexo & $\mathrm{n}$ & Média & DP & $\mathrm{t}$ & $\mathrm{p}$ \\
\hline \multirow{2}{*}{ Preocupação com a equipe } & Feminino & 51 & 31,33 & 3,33 & \multirow{2}{*}{1,82} & 0,072 \\
& Masculino & 27 & 29,89 & 3,32 & & \\
Características de liderança & Feminino & 51 & 29,16 & 2,68 & \multirow{2}{*}{0,25} & 0,805 \\
& Masculino & 27 & 29,00 & 2,62 & & \\
\multirow{2}{*}{ Formas de comunicação } & Feminino & 51 & 40,10 & 3,88 & \multirow{2}{*}{0,18} & 0,855 \\
\multirow{2}{*}{ Preocupação com a tarefa } & Masculino & 27 & 39,93 & 4,09 & & \\
\multirow{2}{*}{ Preocupação com o humano } & Feminino & 51 & 40,02 & 3,43 & 0,97 & 0,337 \\
& Masculino & 27 & 39,30 & 2,51 & & \multirow{2}{*}{0,009} \\
\hline \multirow{2}{*}{ HTE Total } & Feminino & 51 & 35,51 & 2,97 & $2,68^{*}$ & \multirow{2}{*}{0,134} \\
\hline
\end{tabular}

* Diferença estatisticamente significativa no nível de 1\%.

Comparando, por sua vez, os escores em relação ao sexo (Tabela 2), evidenciou-se que, na categoria preocupação com o humano, existe uma diferença estatisticamente significativa entre os dois grupos de professores, ou seja, as mulheres são mais preocupadas com o humano $(\mathrm{p}=0,009)$ do que os homens. E, na dimensão total que avalia a habilidade para o trabalho em equipe, não há uma diferença significativa, mas próxima da significância $(\mathrm{p}=0,072)$, que sugere que as mulheres têm este atributo mais do que os homens.

Destaca-se, ainda, que não foram encontradas diferenças estatisticamente significativas entre os dois grupos, no que se refere às variáveis: faixa etária, tempo de docência e formação acadêmica.

\section{Discussão}

$\mathrm{Na}$ atualidade, é importante que as pessoas, cada vez mais, possam desenvolver habilidades para o trabalho em equipe, quesito este valorizado para o ingresso no mercado de trabalho e que tem sido um diferencial entre profissionais de variadas áreas de atuação. $\mathrm{O}$ trabalho em equipe nem sempre é visto como fácil, e para muitos se configura como um desafio, tendo em vista as características que lhe são inerentes.

Assim, ao proceder à análise das características e habilidades necessárias para o trabalho em equipe, observa-se que, entre a amostra estudada, preocupação com a tarefa foi a que obteve o maior escore padronizado $(4,42)$, sendo, portanto, a categoria mais valorizada entre 
os professores. Com base nos estudos de Monteiro e colaboradores (2002), engloba aspectos de dinamismo, responsabilidade, motivação, competência técnica e planejamento, corroborando o pressuposto que, entre tantos outros, demonstrar interesse pelo que faz e, principalmente, gostar do trabalho que realiza é de fundamental importância no exercício da tarefa docente. Acompanhando essa idéia, Gil (1997) ressalta que é importante para o desempenho do professor universitário de ensino superior o domínio do conhecimento referente à disciplina que ministra e, sempre que possível, à prática profissional. Nessa mesma ótica, Pacheco e Flores (1999) acrescentam que o professor que compartilha seu saber jamais deixa de aprender, uma vez que o ensino se torna uma atividade que exige constante evolução e adaptação a novas situações.

A categoria preocupação com o humano $(4,36)$, que, por sua vez, avalia aspectos como solidariedade, postura ética e empatia (Monteiro e colaboradores, 2002), foi a segunda mais valorizada entre a amostra.

É interessante observar, inclusive, que, nessa categoria, as mulheres tiveram resultados mais altos que os homens, ratificando os achados de Romero, Strey e Marques (2001) acerca de determinadas habilidades e capacidades, próprias do feminino, como a empatia, tolerância, paciência, facilidade de comunicação e de interação, hoje consideradas sobremodo importantes no mundo do trabalho. Paralelamente, um estudo, conduzido por Monteiro, Serafim e Souza (2005), evidencia também diferenças significativas entre os sexos, indicando que as mulheres se preocupam mais com as pessoas do que os homens.

Nessa mesma categoria, considerando a área de atuação, os professores das ciências da saúde mostram-se um pouco mais preocupados com o humano, dada a diferença encontrada $(p=0,068)$ estar muito próxima ao valor estatisticamente significativo $(\mathrm{p}=0,05)$. Esse resultado pode ser atribuído aos aspectos de assistência e preocupação com as pessoas, característico dos profissionais da área, que, aliás, é formada em maior número $(80 \%)$ por professores do sexo feminino. McAllister e Irvine (2002) salientam a importância da empatia, que envolve aspectos afetivos, cognitivos e comportamentais em professores, e a necessidade de se buscar programas educacionais que procurem desenvolver a disposição para capacidade empática em futuros e atuais educadores.

A categoria característica de liderança $(4,16)$ foi a terceira mais valorizada entre os professores desse estudo, englobando orientação para a liderança, segurança pessoal e delegação (Monteiro e colaboradores, 2002). Neste aspecto, é indicado, então, que o professor exerça a função de líder, e não a de autoridade. Nesse sentido, é necessário que ele tenha segurança pessoal suficiente para inspirar confiança, ser respeitado, ser firme nas decisões, administrar com eficácia as diferenças e os conflitos e, paralelamente, saber delegar tarefas acreditando no potencial de cada um, explorando e estimulando a sua criatividade, no sentido da qualidade do processo ensinoaprendizagem. Cabe ressaltar que, para Bock (1996), o professor pode servir como um modelo de liderança a ser seguido pelo aluno.

A categoria formas de comunicação $(4,00)$, que, por sua vez, avalia aspectos relacionados a ser comunicativo e bem humorado (Monteiro e colaboradores, 2002), foi a quarta mais valorizada. Esse achado vem corroborar o pressuposto de que formas efetivas de comunicação, onde se saiba expor, ouvir, trocar idéias e, principalmente, dar e receber feedback, são prerrogativas no processo ensino-aprendizagem e na relação professor $\mathrm{x}$ aluno(s). Outrossim, como bem enfatizam Cohen e Finck, (2003), "as pessoas têm maior probabilidade de desenvolver, mutuamente, sentimentos positivos" (p. 88). Nessa perspectiva, equipes, onde a comunicação não é eficiente, onde as pessoas não costumam interagir umas com as outras, têm maior tendência ao fracasso. Já outro estudo (Andrew, Cobb \& Giampietro, 2005) destacou que a habilidade verbal, como medida isolada, não serve como preditor da eficácia do professor, apesar de ter encontrado que professores fracos têm baixos escores nessa habilidade. No entanto, essa aptidão não se mostrou eficaz para discriminar o bom do excelente educador.

Uma pesquisa sobre as qualidades requeridas para o professor/educador (Koster, Brekelmans, Korthagen \& Wubbels, 2005) salientou como competências consideradas necessárias para o bom desempenho da profissão: ter excelentes habilidades de comunicação e estar atualizado na sua área profissional, características estas que também obtiveram pontuações mais altas neste estudo. Koster e colaboradores (2005) destacaram ainda, como importantes na docência, as atribuições de dar e receber orientação e suporte dos colegas; e também ser continentes para com os seus alunos, atributos estes que remetem à preocupação com o humano, que apareceu como o terceiro fator mais pontuado nesta pesquisa.

Comparando os resultados das cinco categorias, em relação às áreas de atuação, observa-se que não há diferença estatisticamente significativa entre os dois grupos. Assim, tanto na área das ciências da saúde, como das exatas, as características e habilidades necessárias para o trabalho em equipe são positivamente valorizadas no exercício da docência. Esse resultado retrata que os professores, independentemente da sua área de atuação, reconhecem tais habilidades como importantes ou, talvez, essenciais no seu perfil profissional. Sem dúvida, não 
basta apenas reconhecê-las, é preciso mais do que isso. Desenvolvê-las, com certeza, permitirá que esses profissionais possam exercer sua docência com maior e melhor qualidade.

\section{Considerações finais}

A trajetória percorrida ao longo do presente estudo ratifica a importância das habilidades para o trabalho em equipe no exercício profissional e, de modo particular, entre professores universitários, os quais, independentemente da área de atuação, as reconhecem e valorizam.

Paralelamente, destaca as possíveis contribuições que a ciência psicológica pode dar em relação ao fenômeno estudado. Ocupar-se do exercício da docência, para além das questões didático-pedagógicas, privilegiando o desenvolvimento de habilidades necessárias para o trabalho em equipe, é, sem dúvida, tarefa de grande magnitude. Nesse espaço de intervenção, é inegável a importância da avaliação psicológica, bem como dos seus instrumentos, tanto nas tarefas de diagnóstico como de treinamento/ desenvolvimento. Espera-se, por fim, que esta pesquisa, ao explorar e descrever tais habilidades junto aos professores universitários, represente uma ínfima parcela a somar entre outras tantas que suplantem suas limitações.

\section{Referências}

Andrew, M. D., Cobb, C. D. \& Giampietro, P. J. (2005). Verbal ability and teacher effectiveness. Journal of Teacher Education, 56, 343-354.

Bock, V. R. (1996). Professor e psicologia aplicada na escola. Porto Alegre: Kinder.

Cohen, A. R \& Finck, S. L (2003). Comportamento organizacional: conceitos e estudos de casos. Rio de Janeiro: Campus.

Delors, J. (2003). Educação: um tesouro a descobrir (8 $\left.{ }^{\mathrm{a}} \mathrm{ed}.\right)$. São Paulo: Cortez; Brasília: MEC, UNESCO.

Enricone, D. (Org.) (2004). Ser professor (4 ${ }^{\mathrm{a}} \mathrm{ed}$.) Porto Alegre: EDIPUCRS.

Fleury, M. T. L. (Coord.) (2002). As pessoas na organização. São Paulo: Gente.

Gil, A. C. (1995). Métodos e técnicas de pesquisa social. São Paulo: Atlas.

Gil, A. C. (1997). Metodologia do ensino superior. (3 ${ }^{\mathrm{a}}$ ed.) São Paulo: Atlas.
Goulart, I. B. (2002). Psicologia organizacional e do trabalho: teoria, pesquisa e temas correlatos. São Paulo: Casa do Psicólogo.

Isaia, S. M. A. \& Bolzan, D. P. V. (2004). Formação do professor do ensino superior: um processo que se aprende? Revista do Centro de Educação da Universidade Federal de Santa Maria, 29, 1-10.

Koster, B., Brekelmans, M., Korthagen, F. \& Wubbels, T. (2005). Quality requirements for teacher educators. Teaching and Teacher Education, 21, 157-176.

Lima, T. L. (1999). Manual básico para a elaboração de monografia. Canoas: ULBRA.

Marras, J. P. (2000). Administração de recursos humanos: do operacional ao estratégico ( $3^{\mathrm{a}}$ ed.). São Paulo: Futura.

Mcallister, G. \& Irvine, J. J. (2002). The role of empathy in teaching culturally diverse students: A qualitative study of teachers' beliefs. Journal of Teacher Education, 53, 433-443.

Monteiro, J. K., Ribeiro, E. A., Serafim, S. M. A. \& Souza, F. P. (2002). Habilidade para trabalhar em equipe. Aletheia, 16, 7-14.

Monteiro, J. K., Serafim, S. M. A. \& Souza, F. P. (2005). Investigando diferenças na habilidade para o trabalho em equipe quanto ao sexo - idade e escolaridade [Resumos]. Anais do II Congresso Brasileiro de Avaliação Psicológica: Desafios para a formação, prática e pesquisa (pp. 5). Gramado: Ibap.

Moscovici, F. (2003a). Equipes dão certo: a multiplicação do talento bumano ( $8^{\mathrm{a}}$ ed.). Rio de Janeiro: José Olympio.

Moscovici, F. (2003b). Desenvolvimento interpessoal: treinamento em grupo $\left(13^{\mathrm{a}}\right.$ ed.). Rio de Janeiro: José Olympio.

Pacheco, J. A. \& Flores, M. A. (1999). Formação e avaliação de professores. Porto: Porto Ed.

Parker, G. M. (1994). Team players e tenwork - a equipe e seus integrantes: a nova estratégia competitiva. São Paulo: Pioneira.

Pasquali, L. (Org.) (1999). Instrumentos psicológicos: manual prático de elaboração. Brasília: LabPAM; IBAPP.

Pasquali, L. (2003). Psicometria: teoria dos testes na psicologia e na educação. Petrópolis, RJ: Vozes.

Perrenoud, P. (2000). 10 novas competências para ensinar. Porto Alegre: Artes Médicas.

Romero, S. M, Strey, M. N. \& Marques, J. C. (2001). Relações de gênero na escolha da profissão de administrador/a: uma pesquisa preliminar com estudantes. Revista Psico, 32, 39-59. 
Sadalla, A. M. F. A., Wisnivesky, M., Saretta, P., Paulucci, F. C., Vieira, C. P. \& Marques, C. A. E. (2005). Partilhando formação, prática e dilemas: uma contribuição ao desenvolvimento docente. Psicologia Escolar e Educacional, 9(2), 71-86.

Spector, P. E. (2003). Psicologia nas organizacõoes. São Paulo: Saraiva.

Sobre as autoras:

Fernanda Pasquoto e Souza é graduada em Psicologia pela Universidade Luterana do Brasil (2005). Atualmente é mestranda em Ciências Médicas: Psiquiatria na Universidade Federal do Rio Grande do Sul (UFRGS), pesquisadora da Universidade de São Paulo (USP) e do Hospital de Clínicas de Porto Alegre e psicoterapeuta do Instituto Cyro Martins. Tem experiência na área de Terapia Cognitivo-Comportamental e trabalho em equipe.

Janine Kieling Monteiro é graduada (1992) e doutora (2000) em Psicologia pela Universidade Federal do Rio Grande do Sul (UFRGS). Atualmente é professora do Mestrado em Psicologia Clínica da UNISINOS, onde desenvolve pesquisa na temática saúde e trabalho. Tem experiência nas áreas de Psicologia do Trabalho e Avaliação Psicológica.

Gisele Beatriz Zatt Elgues é graduada em Psicologia pela Universidade do Vale do Rio dos Sinos (1986), com especialização em Diagnóstico Psicológico pela Pontifícia Universidade Católica do Rio Grande do Sul (1992) e mestrado em Psicopatologia e Psicologia Clínica pelo Instituto Superior de Psicologia Aplicada (1999). Atualmente é professora e pesquisadora do Curso de Psicologia da Universidade Luterana do Brasil. Tem experiência na área de Psicologia, com ênfase em Avaliação Psicológica e Psicologia Escolar e Educacional. 